\title{
Early Lessons and Challenges from the Healthy Mendocino Community of Solution
}

\author{
Susan Baird Kanaan, MSW
}

Northern California's Mendocino County is joining the national movement to upgrade the quantity and quality of local data available for assessing and improving local health. A broad-based coalition in the county has successfully engaged 20 community partners in funding a web-based tool for this purpose. HealthyMendocino.org, launched in January 2013, is designed to support setting local priorities, planning and evaluating the program, and building community by giving easy access to timely data on 90 indicators of local health and its determinants compiled from a range of state and federal sources. This article, written before the site's launch by the Chair of the Healthy Mendocino Steering Committee, describes the community of solution that came together to envision, publicize, raise support for, and bring to fruition this new resource. Mendocino is a rural county with limited financial capacity but rich social assets, including a strong collaborative tradition and an infrastructure of dynamic coalitions. This article outlines the anticipated benefits, early lessons, and challenges of the initiative and explains how the organizers leveraged connections with other communities of solution that already are working to improve the quality of life in the area. The article also notes ways in which this local initiative illustrates and aligns with several of the grand challenges outlined in the modern Folsom Report-specifically, challenges $7,8,11,12$, and above all 13 , which concerns the use of health information technology to enable the flow of knowledge to the community of solution. (J Am Board Fam Med 2013;26:316-322.)

Keywords: Communication, Community Medicine, Environmental Health, Patient Education, Public Health, Rural Health, Social Problems

Mendocino County, located 120 miles north of San Francisco, is known for its beautiful coastline, redwoods, wine, and other agriculture (Figure 1). Its 88,000 residents are spread across 3,500 square miles. Ukiah, with 15,000 residents, is the county seat and the largest of its 4 incorporated cities and towns. Of all county residents, $22 \%$ are Latino and $5 \%$ are Native American. ${ }^{1}$ Nearly $18 \%$ of the population $^{1}$ and $30 \%$ of the county's children ${ }^{2}$ live in poverty. Local health indicators are to a large extent in line with those of California; in many cases,

This article was externally peer reviewed.

Submitted 29 August 2012; revised 1 February 2013; accepted 6 February 2013.

From the Healthy Mendocino Steering Committee and Mendocino County Health and Human Services Agency Advisory Board, Ukiah, CA.

Funding: none.

Conflict of interest: none declared.

Corresponding author: Susan Baird Kanaan, Healthy Mendocino Steering Committee, 621 Capps Lane, Ukiah, CA 95482 (E-mail: susanbairdkanaan@yahoo.com). both are well below national benchmarks. County residents' health behaviors related to obesity, smoking, and alcohol and drug abuse are among the major concerns. ${ }^{2}$ Local services already are stretched thin after repeated cuts to the staff and budgets of government agencies and community partners, and further cuts are feared in the future.

Given this environment, it was a bold move for a coalition of volunteers and organizations to set out in mid-2011 to bring a web-based tool with information on local health and well-being to the people of Mendocino County. Yet in just a year, the coalition succeeded in stimulating keen interest in this new resource, engaging 20 community partners and raising the necessary funds to license and develop HealthyMendocino.org. The website, launched on January 1, 2013, provides user-friendly access to regularly updated public data on local health and its determinants from 15 state and federal sources, along with monitoring and comparison tools and a national database of promising 
Figure 1. Map of Mendocino County.

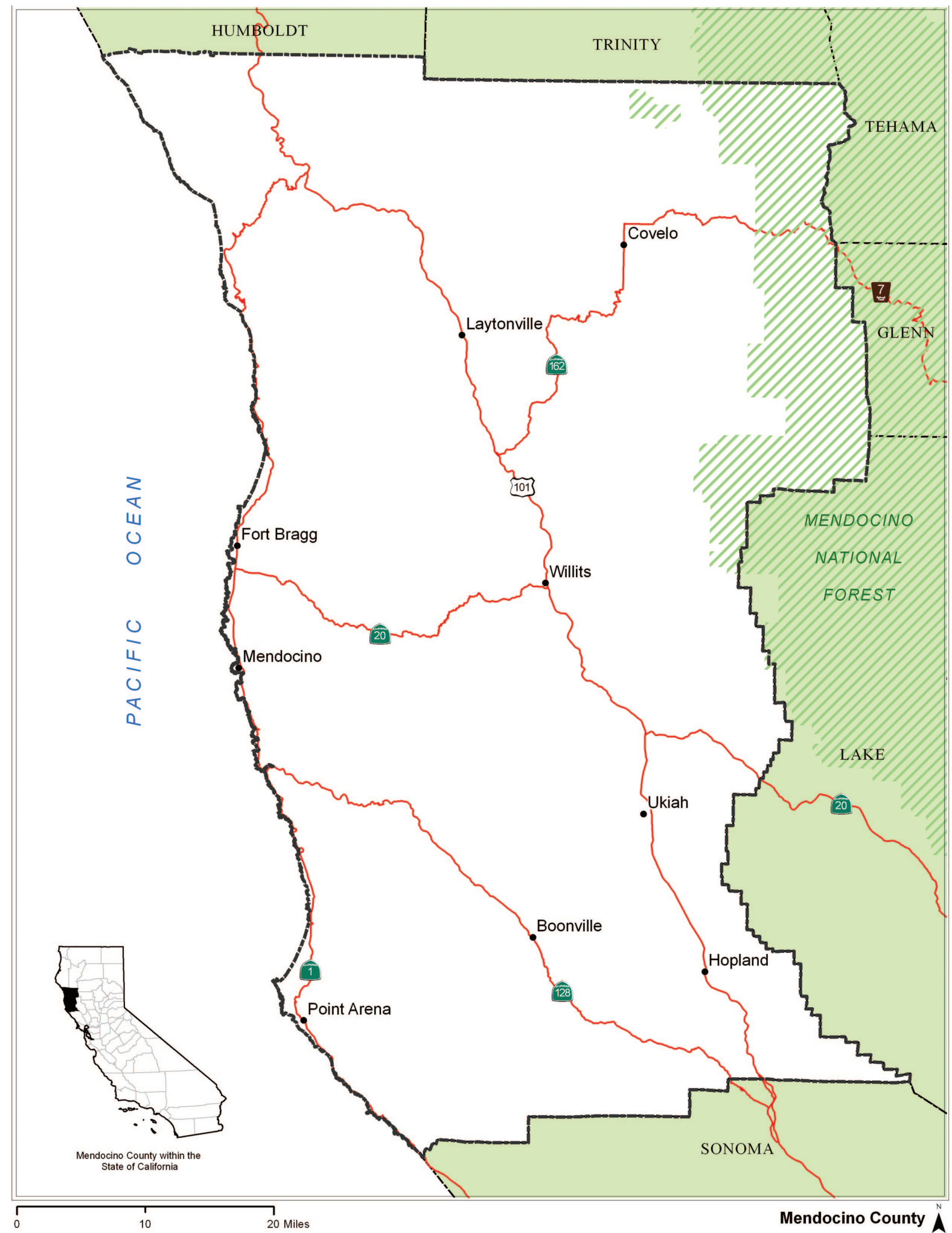


community health practices. In addition, it features a community calendar, reports and stories about local issues and initiatives, links to community partners' web sites and the service referral directory 211 , and several personal health management tools. What made this new investment possible in a time of intensely competing demands on tight budgets was a combination of a collaborative culture, preexisting coalitions, favorable timing, and broad recognition of the potential benefits of a shared information platform.

\section{Collaboration and Coalitions in Mendocino County}

The area's tradition of collaborative problem-solving and network of coalitions provided fertile soil for the growth of the Healthy Mendocino initiative. Listed below are examples of the broad-based communities of solution already hard at work to improve health and well-being in the area.

- The county's Health and Human Services Agency (HHSA) collaborates with community partners to carry out many public health and social service programs, including homeless services, family wellness, and children's health insurance initiatives. The HHSA works with its advisory board, whose members have wide-ranging expertise, to promote communication between HHSA, health care providers, and community-based organizations. The advisory board participates in HHSA's strategic planning and advises on program priorities. Both HHSA and the Alliance for Rural Community Health $(\mathrm{ARCH})$ were early supporters of Healthy Mendocino.

- Through ARCH, 8 community health centers collaborate to improve access to and the efficiency of health care across the county and to carry out a prevention initiative funded by The California Endowment.

- A coalition of hospital, law enforcement, and safety net organizations called CUSOC (named for its target population: chronic users of the system of care) is working to reduce the high cost of caring for this population through better case management and care coordination.

- A food policy and action network coordinates efforts to strengthen local food production and distribution and improve the food consumption practices of local residents. One of the many projects aligning community health and food is an initiative that doubled the buying power of food stamps (CalFresh) at farmers' markets to encourage consumption of fresh, locally produced food.

\section{The Process: Need Meets Opportunity}

Since 1996, health and social service organizations in the county have relied on the Mendocino County Community Health Status Report, a printed resource compiled biannually by HHSA's statistician, for local health data. In 2011, the statistician's impending retirement coincided with growing awareness of HealthySonoma.org, the website of neighboring Sonoma County. ${ }^{3}$ With the public increasingly expecting to find needed information on the Internet, community leaders wanted to see Mendocino County move in this direction. Data users in HHSA and on its advisory board saw the potential benefits of having online access to comprehensive, regularly updated local data and new comparison, tracking, and communication tools. Some members already were familiar with the ways Sonoma County was using its website to support community health planning and encourage physical activity. Healthy Communities Institute (HCI), the Berkeley-based developer of HealthySonoma.org and other Healthy Communities Network sites around the United States, recently had won an award at the U.S. Department of Health and Human Services' Health Datapalooza, a fact that added to its credibility and appeal.

After arranging a summertime demonstration of HCI's products and services to the advisory board, a small group of organizers spent several months laying groundwork through planning meetings, conversations with community leaders, and consultations with other members of HCI's Healthy Communities Network. Then, at the end of 2011, the advisory board adopted Healthy Mendocino as a project and created a steering committee to move it forward. The steering committee's members represent community health centers, local government, community-based organizations, and a local foundation. There was broad agreement that Healthy Mendocino should be a community-driven resource, and North Coast Opportunities, a local nonprofit organization, stepped forward to serve as its contractual fiscal agent. 
Next, we turned our attention to spreading the word about Healthy Mendocino and securing funding commitments. Our initial goal of $\$ 50,000$ covered HCI's start-up and first-year licensing costs plus a small margin for local expenses. In the current economic climate, and with no large businesses in the county, this relatively modest amount was enough to require a concerted fundraising effort and careful discernment by potential funding partners. We cast a wide net, reaching beyond the "usual suspects" in public health and health care to talk with community development leaders, local foundations, the director of a local credit union, members of local government, our Congressional staffer, the sheriff, and many others.

A February 2012 presentation to the county board of supervisors and local hospital representatives yielded an endorsement by the board of supervisors and interest on the part of the hospitals. The first pledges of financial support came from HHSA and the organizations of several advisory board members; soon, 2 hospitals signed on, and by June 2012-just a year after the idea of Healthy Mendocino was first brought to the HHSA advisory board-we had secured first-year funding and laid the groundwork for ongoing support. The contributions from a diverse array of funding partners, including 7 community-based organizations, 5 community health centers and their consortium, 2 hospitals, 2 local foundations, the county HHSA, the sheriff's office, and a credit union, ranged from $\$ 250$ to $\$ 15,000$ and were primarily in the range of $\$ 1,000$ to $\$ 2,000$. With funding assured, we signed a contract and announced a public launch date of January 1, 2013.

The HCI's client communities around the United States exhibit a fascinating variety of models for structuring local support. ${ }^{4}$ While the sites of Sonoma and San Francisco Counties, for example, are supported by a few large funders, our Mendocino County site depends on a large number of funding partners. We regard our broad base as highly advantageous: the partners' participation gives HealthyMendocino.org a solid foundation and imprimatur, assures a core of initial users, and lends stability to the project. Moreover, we expect to reach out through the partners' communication networks and to collaborate with them in building public awareness of the new information resource and its potential uses.
As of this writing, we are preparing local content (unique reports, news and feature stories, a calendar, policy statements, and an interactive feature) and planning staffing, community outreach, and future funding. The data in the site's Community Dashboard consist of more than 100 local indicators compiled from at least 20 public sources. Together, they constitute HCI's core set of indicators, customized for each community. Eventually we may augment this content with locally collected data, as discussed below. The local staffing to complement HCI's licensed support will come from a patchwork of services from a volunteer from the AmeriCorps' Volunteers in Service to America, the information technology coordinator of fiscal agent North Coast Opportunities, and a small slice of time from an HHSA public health analyst, all of which will be coordinated by the steering committee.

\section{Aspirations and Intentions: What Do We Hope to Achieve?}

A new information resource is a kind of blank slate onto which different people project different hopes and expectations. The organizations and professionals who already use local data on health and its determinants in their work are the primary audience and user base for HealthyMendocino.org. Virtually every funding partner and steering committee member represents an entire network of potential users and beneficiaries. The chief expectation among these core supporters is that their organizations will now have easier access to a strong evidence base that they can use to set priorities, create proposals and reporting for grants, plan and evaluate programs, and educate the community. These leaders' awareness of the potential benefits has provided the motive force for the initiative. Organizations that have relied on the biannual, printed Community Health Status Report for data or on laborious searches of one data source after another anticipate that the new resource will free up staff time for other purposes. By enabling this redirection of human resources and providing a stronger evidence base, HealthyMendocino.org can heighten the effectiveness of existing programs and agencies.

To cultivate the secondary audiences for the website, the steering committee will actively encourage its use by all initiatives and projects work- 
ing to improve life in Mendocino County, including those working on health matters and those focused on determinants such as housing, education, land use, food, the environment, and economic development. Having a common tool that covers all these factors can facilitate convergence around shared priorities and create synergies and economies of scale. An early opportunity is to enhance the connections between public health and food-related work and to increase awareness of these activities. Such interconnections can in turn stimulate and support new communities of solution.

Finally, the steering committee regards all county residents as potential HealthyMendocino.org audience members. On a concrete level, the website offers useful health management tools, a resource directory, and a community calendar. In a more abstract sense, the website establishes a broad context for health and health action, with the potential to increase understanding of health as "a community affair" ${ }^{5}$ in which residents play key roles as co-creators of a healthy community. The combination of data on local health status with data on the determinants of health highlights the many entry points for constructive action.

The long-term vision outlined here will only be realized over time through education and outreach. The steering committee plans to promote these developments through presentations, media outreach, tailored users' guides, training opportunities, and more.

\section{Early Lessons}

Although the Healthy Mendocino project is at a very early stage of development, our local experience has already yielded a number of early lessons.

- The hunger for better data on local health and well-being is shared by a diverse range of community members and organizations, extending well beyond public health and health care. The broad support for Healthy Mendocino expresses the felt need for better data and easier data access and communication.

- Preexisting coalitions can form a scaffolding on which new communities of solution can be built.

- Hospitals and community health centers will join and support a community-led venture that they see as aligned with their objectives. Through such alliances, health care organizations can create a bridge between overstretched health care professionals and opportunities for community action.

- Local limitations can prompt communities of solution to look broadly for ways to strengthen local capacities. Buying or leasing an appropriately scaled and customized product and service is a way to supplement local capacities with a road-tested tool.

\section{Immediate and Anticipated Challenges}

The Healthy Mendocino initiative faces practical, conceptual, and values-based challenges. An early one came in the form of push-back from a local health information networking expert who might well have supported the effort, knowing the importance of evidence-based decision making. Instead, citing the severe cutbacks and service gaps in the county, this long-time resident expressed concern that the project would divert money from more critical uses. His response prompted the organizers to re-examine our thinking and, having reaffirmed our reasoning, to hone our talking points. Still, his legitimate question about priorities, albeit voiced by a single critic, increases our determination to do all we can to maximize the return on this community investment.

The return depends, of course, on the use of this tool for public benefit - and that, too, is a community affair. The broad task of using information to improve community health rests with the many public and private organizations and individuals working toward that goal; the more focused task of defining and achieving success for HealthyMendocino.org belongs to that initiative's organizers and supporters. For the latter, the questions include, How can we maximize the website's usability and usage?, What will make it as relevant as possible for all segments of the population, including the large Spanish-speaking and bilingual population?, and What metrics will we use to evaluate success? Having focused in its first year on making the new resource available to the community, the steering committee will address these critical questions in collaboration with community partners in the next stage of its work.

As those who work with local data can attest, even under the best of conditions there are limits to the usability of publicly available local data. These 
limitations range from the common lack of enough granularity for targeted analysis to the lack of agreed-on summary measures for assessing, tracking, and comparing local health. Our young local initiative will have to operate within these limitations. At the same time, they may create yet another challenge by spurring interest in finding and posting locally collected data to fill data gaps. This creates a paradox, for while doing so could augment the core indicators in HealthyMendocino.org with relevant local data, it also raises questions about data quality, privacy protection, and the ability to keep locally collected data up to date.

Many of these issues point to an overarching challenge: this project is managed entirely by a widely distributed group of busy volunteers, many of them chief executive officers of their own organizations. This in turn has implications for the ultimate challenge: sustainability — of funding, staff support, and local content-and stimulating enough usage and benefits to justify them all.

\section{Alignments with the Grand Challenges Defined in the Modern Folsom Report}

Both as a community-based initiative and as a webbased resource, Healthy Mendocino illustrates and aligns with many of the 13 grand challenges discussed in "Communities of Solution: The Folsom Report Revisited" (the challenges are summarized in Table 1 of that publication). The pivotal challenge is no. 13, concerning the use of health information technology and data-sharing networks to enable the flow of relevant knowledge to the community of solution. Knowledge flow and communication through the website can help community leaders identify and build consensus around priority health issues and facilitate efforts to improve health and quality of life in the county. The most relevant additional grand challenges with which this initiative aligns are evolving partnerships for creating healthy living environments (challenge 7); growing participation in health promotion by a population that has increasing levels of health literacy (challenge 8); more effective collaboration between public health and medicine (challenge 11); and the growth of a citizen volunteer network that is able to advocate for policies, resource allocation, and actionable data to support all these activities (challenge 12).

\section{Toward Broader Communities of Solution}

The limitations faced in Mendocino County are typical of those in rural areas. For example, with only a community college in the area, few experts are available to lead community-based research. Such research can drive community engagement and change, but it cannot be conducted without adequate research and analytic capacities. Another limitation is that rural primary care professionals can be far too overstretched and isolated to engage in the community in the ways envisioned for "the ideal primary care physician" in the aforementioned article about the Folsom Report. ${ }^{6}$

Challenges such as these make it necessary to augment local efforts and resources in creative ways. For example, can outside entities such as academic researchers residing elsewhere, networks of public health professional, or regional extension centers help communities like Mendocino County make fuller use of data to improve local health? Possible solutions might include bringing in visiting experts to coach community leaders; creating mutual support mechanisms with other HCI clients, especially those in the immediate area; or organizing regional Datapaloozas based loosely on the national model.

\section{Tools for Using Public Data: Reflections on a Public Policy Issue}

The Mendocino County story offers a lens on a contemporary public policy question. The natural result of the federal government's energetic "data liberation" initiative is that more federal data on health and health determinants are becoming available to communities. Increased release of data does not necessarily translate into increased use of local data, however, because the latter depends on adequate local infrastructure, expertise, and readiness. This is a version of the proverbial "last mile" problem. In its 2011 study of local data issues, the National Committee on Vital and Health Statistics found that many U.S. communities, large and small, lack the expertise to collect, display, protect, and make full use of local data. ${ }^{7}$ Mendocino County is no exception. As the federal government releases a growing volume of data, this digital divide will widen unless there is a concerted effort to mitigate it. The National Committee on Vital and Health Statistics report suggests a number of approaches to this end. 
Current federal policy looks in part to the private sector for proprietary solutions by spurring private developers to create web tools and mobile applications to make publicly available data more usable. For example, the U.S. Department of Health and Human Services has created a Working Group on Health and Human Services Data Access and Use to explore federal data assets, local needs, and innovative ways to bridge the two. Outsourcing some functions to private sector experts may, indeed, be a cost-effective alternative to any possible home-grown solutions, given the expertise needed to design high-power interfaces with public data sources and the limits and costs associated with local workforces.

Here in Mendocino County, recognizing our own limitations, we have chosen to use a proprietary tool to meet our local data and information needs. We know that this new resource is not something we could have created for ourselves, and we value the fact that it comes tested and recommended by other communities. The Healthy Mendocino initiative described in these pages already has produced benefits and stimulated new forms of collaboration; this makes us optimistic that it will generate more of both as it develops. In addition, it is likely to increase our capacity to make use of additional public data as they become available in the future. From a broader national perspective, it is worthwhile to consider what approaches will en- able communities of all kinds across the country to derive maximum value, at minimal expense, from the rich store of public data now being made available to them.

\section{References}

1. US Census Bureau. State \& county quickfacts. Mendocino County, California. Available from http:// quickfacts.census.gov/qfd/states/06/06045.html. Last updated January 10, 2013; accessed March 11, 2013.

2. County Health Rankings. United States, California, Mendocino (ME), 2012. Available from http:// www.countyhealthrankings.org/app\#/california/ 2012/mendocino/county/1/overall/snapshot/by-rank. Accessed April 8, 2013.

3. The Healthy Communities Institute. Healthy Sonoma. Available from www.healthysonoma.org. Accessed March 26, 2013.

4. Healthy Communities Institute. Healthy communities network. Available from http://www. healthycommunitiesinstitute.com/healthy-communitiesnetwork-2/. Accessed April 8, 2013.

5. Roberts DW. Health is a community affair. Preview of the Final Report of the National Commission on Community Health Services. JAMA 1966;196:332-3.

6. The Folsom Group. Communities of solution: the Folsom Report revisited. Ann Fam Med 2012;10: 250-60.

7. National Committee on Vital and Health Statistics. The Community as a Learning System: Using Local Data to Improve Local Health. 2011. http:// www.ncvhs.hhs.gov/111213chip.pdf. Accessed March 11, 2013. 